Résumés des conférences et travaux

\title{
Papyrologie grecque
}

Jean-Luc Fournet

\section{(2) OpenEdition \\ Journals}

Édition électronique

URL : https://journals.openedition.org/ashp/4238

DOI : $10.4000 /$ ashp.4238

ISSN : 1969-6310

Éditeur

Publications de l'École Pratique des Hautes Études

\section{Édition imprimée}

Date de publication : 1 septembre 2021

Pagination : 144

ISSN : 0766-0677

\section{Référence électronique}

Jean-Luc Fournet, « Papyrologie grecque », Annuaire de l'École pratique des hautes études (EPHE), Section des sciences historiques et philologiques [En ligne], 152 | 2021, mis en ligne le 14 juin 2021, consulté le 15 juin 2022. URL : http://journals.openedition.org/ashp/4238 ; DOI : https://doi.org/ $10.4000 / a s h p .4238$ 


\title{
PAPYROLOGIE GRECQUE
}

\author{
Directeur d'études : M. Jean-Luc FourneT
}

Programme de l'année 2019-2020 : I. Initiation à l'édition et à la critique textuelle des papyrus. - II. Étude de papyrus inédits.

Cette année a été consacrée au déchiffrement et à l'étude d'un codex de tablettes inédit de la British Library (BLAdd. Ms. 33369) dont l'édition fait l'objet d'une collaboration avec T. Hickey (Berkeley), Valérie Schram et Yasmine Amory (docteures de l'EPHE, postdoctorantes respectivement à Oslo et Gand). Constitué de dix tablettes en bois qui, à l'exception des deux faces externes, présentent une surface à écrire revêtue d'un enduit blanc et encadrée par une bordure rectangulaire plus épaisse, ce codex contient 16 documents écrits en grec. Ceux-ci ont tous Panopolis comme lieu de rédaction, ce qui assure la provenance panopolitaine de ce codex. L'un d'entre eux contenant une formule de serment par l'empereur Zénon (r. 474-491) permet de dater la copie de ces textes de la fin du $\mathrm{V}^{\mathrm{e}}$ siècle.

À l'exception du dernier, les documents sont tous de la même main. Cette dernière est extrêmement malhabile, et le déchiffrement des textes a vite montré que la maîtrise du grec n'était guère plus satisfaisante. À l'évidence, nous avons affaire à un apprenti-scribe. Outre le support, typique de l'école, le fait que les textes sur lesquels il s'exerce sont presque tous des contrats incite à penser que l'on a affaire au cahier d'un élève se formant au métier de notaire. Ces conclusions sont confirmées par l'anonymisation que l'on a fait subir aux contrats : les noms des parties ont été systémati-

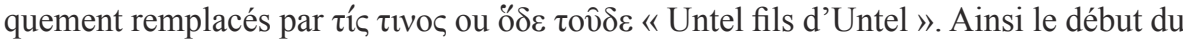

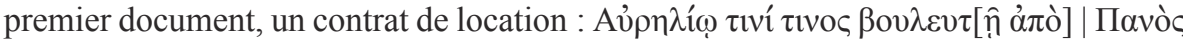

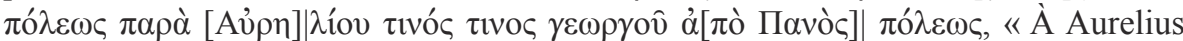
Untel fils d'Untel, sénateur, [originaire de] Panopolis, de la part d'Aurelius Untel fils d'Untel, agriculteur, originaire de Panopolis ».

Toutes ces caractéristiques font de ces tablettes un rare et précieux témoignage de l'éducation professionnalisante dans l'Antiquité tardive, qui, dans le domaine du notariat, est extrêmement mal connue et n'a jusqu'ici retenu que peu l'attention des chercheurs.

Le déchiffrement de ces tablettes a été interrompu par le premier confinement et sera poursuivi et achevé en 2020-2021. Le lecteur trouvera donc un compte rendu plus détaillé des résultats auxquels nous serons parvenus dans le prochain annuaire.

Pour la partie de la conférence qui s'est déroulée au Collège de France, voir l'Annuaire du Collège de France, 120, 2019-2020 (sous presse). 